\title{
DETERMINACIÓN ELECTROQUÍMICA DE PLOMO Y CADMIO EN AGUAS SUPERFICIALES
}

\author{
Claudia Macías Socha \\ Mauricio García Colmenares (iD ${ }^{2}$ \\ Patricia Chaparro S.
}

Recibido el 9 de junio de 2015, aprobado el 7 de marzo de 2016 y actualizado el 7 de diciembre de 2016

DOI: 10.17151/luaz.2017.44.3

\section{RESUMEN}

El método voltametría de onda cuadrada (OSWV) fue validado para la cuantificación de $\mathrm{Cd}^{2+}$ y $\mathrm{Pb}^{2+}$ en aguas superficiales. El estudio fue realizado usando solución BrittonRobinson como electrolito de soporte a pH 4,8, carbón vítreo como electrodo de trabajo, $\mathrm{Ag} / \mathrm{AgCl}$ como electrodo de referencia y platino como electrodo auxiliar. La técnica presenta un límite de detección $211 \mu \mathrm{g} / \mathrm{L}$ para $\mathrm{Pb}$ y $268 \mu \mathrm{g} / \mathrm{L}$ para Cd. La aplicación de la técnica voltamétrica OSWV fue realizada en aguas de la quebrada Las Torres del sector Parque Industrial en Sogamoso (Colombia), hallando una concentración de: $\mathrm{Pb}^{2}+0,750 \pm 0,067 \mathrm{mg} / \mathrm{L}$ y $\mathrm{Cd}^{2}+0,570 \pm 0,071 \mathrm{mg} / \mathrm{L}$, los cuales sobrepasan los límites máximos establecidos por las normas nacionales (Decreto $4728 / 2010$ ) e internacionales vigentes para aguas residuales. Los resultados fueron contrastados por el método de referencia espectrofotometría de absorción atómica aceptado como referencia, permitiendo deducir que el método electroquímico genera resultados con un nivel de confianza del $95 \%$.

\section{PALABRAS CLAVE}

Voltametría, carbón vítreo, metales pesados, voltagrama.

\section{ELECTROCHEMICAL DETERMINATION OF LEAD AND CADMIUM IN SURFACE WATER}

\begin{abstract}
The square wave electrochemical voltammetry method (OSWV) to quantification of cadmium and lead in surface waters was validated. It used a Britton-Robinson buffer as solution supporting electrolyte to $\mathrm{pH} 4.8$, working electrode glassy carbon, $\mathrm{Ag} / \mathrm{AgCl}$ as reference electrode and platinum as counter electrode. The limit of detection determined was $211 \mu \mathrm{g} / \mathrm{L}$ for $\mathrm{Pb}$ and $268 \mu \mathrm{g} / \mathrm{L}$ for $\mathrm{Cd}$. The application of voltammetric technique OSWV was performed in waters of the creek Towers Industrial Park Sector in Sogamoso (Colombia). The ions concentration in the samples analyzed was $0.750 \pm 0.067 \mathrm{mg} / \mathrm{L}$ for $\mathrm{Pb}^{2}+$ and $0.570 \pm 0.071 \mathrm{mg} / \mathrm{L}$ for $\mathrm{Cd}^{2}+$, exceeding the national and international standards limits for wastewater. The results obtained by voltammetry were compared with atomic absorption method spectrophotometer traditionally accepted, allowing deducing that the voltammetric method generates results with a confidence level of $95 \%$.
\end{abstract}

\section{KEY WORDS}

Voltammetry, vitreous carbon, heavy metals, voltammogram. 


\section{INTRODUCCIÓN}

La Organización Mundial de la Salud (OMS) y la Organización de las Naciones Unidas para la Alimentación y la Agricultura (FAO) reconocen la vulnerabilidad del recurso hídrico en lugares donde persiste la contaminación por metales pesados, así como el impacto negativo de las actividades antropogénicas (OMS, 2008). Una de las causas que contribuyen a la polución de las fuentes hídricas por metales pesados es el material particulado y la descarga de lixiviados industriales, siendo estos un riesgo para el medio ambiente, las actividades agropecuarias y la seguridad alimentaria de las regiones y/o sitios aledaños. Los metales pesados son especies químicas no degradables, por tanto, se consideran contaminantes estables y persistentes al ser depositados al medio ambiente. Esto ocasiona alteraciones en los diferentes ecosistemas e incrementa su solubilidad llegando a reducir la calidad de vida de los seres vivos (Del Toro, González, Bravo \& Mollineda, 2010; Madero \& Marrugo, 2011).

Sogamoso cuenta con una riqueza hídrica considerable, con afluentes como la quebrada Las Torres, una de las quebradas más importantes que recoge los vertimientos de explotaciones minera de Morcá, y la Zona del Corredor Industrial destacándose la producción siderúrgica y cementera, que por su cercanía a dicha quebrada intervienen al generar diferentes tipos de contaminación. Su trayectoria es de oriente a occidente. En la parte alta sus aguas son utilizadas para consumo humano, regadío y abrevadero de animales, en la parte baja para la industria ladrillera, y en la parte media recibe vertimientos de la minería del carbón y las aguas servidas de la comunidad aledaña. En general, está quebrada es de alta vulnerabilidad a la contaminación, por su cercanía a la zona industrial, generando un alto grado de peligrosidad a quien use dicha agua de la quebrada (Identidad Geográfica, 2015).

Los metales, como el plomo $(\mathrm{Pb})$ y el cadmio $(\mathrm{Cd})$, deben su toxicidad a la fuerte afinidad de sus cationes por el azufre, así como hacia los grupos sulfhidrilo, -SH, los cuales están presentes comúnmente en las enzimas que controlan la velocidad de las reacciones metabólicas (Ruiz, 2012). El Pb en el organismo humano puede causar lesiones al sistema urinario, nervioso, reproductor e inmunológico (EPA, 2012), y el Cd puede acumularse en los riñones, donde afecta el mecanismo de filtración causando la excreción de proteínas esenciales y azúcares del cuerpo y el consecuente daño de los riñones, también genera daño en el sistema nervioso central, inmune, y posible daño en el ADN o desarrollo de cáncer (Boguszewska \& Pasternak, 2004; Lenntech, 2015). Así, el $\mathrm{Cd}$ y el $\mathrm{Pb}$ son reconocidos como tóxicos acumulativos y su concentración en aguas de consumo humano según la EPA no puede ser superior de 0,005 mg/L Cd, 0,015 mg/L Pb (EPA, 2012).

Para la determinación de metales pesados a niveles de trazas en el medio ambiente se han desarrollado métodos altamente sensibles y selectivos, entre los que se encuentran la Espectrometría de Masas con Plasma de Acoplamiento Inductivo (ICP$\mathrm{MS})$, Espectrometría de Fluorescencia de rayos $\mathrm{X}$ (XRF) y Espectrometría de Absorción Atómica (AAS) (Ewing, 1997). Sin embargo, el análisis implica tiempos largos, instrumentos sofisticados y costosos, y mantenimiento de alto costo. En contraste, el método electroquímico es una alternativa de amplio espectro, económica, versátil y amigable con el ambiente. Estos métodos son una opción para el análisis de trazas de metales pesados, aniones, sulfuros, nitritos, nitratos y otros compuestos orgánicos en aguas, alimentos, productos químicos y baños galvánicos a niveles de ppt, ppb y ppm. El Cd y el $\mathrm{Pb}$ han sido determinados en agua potable por voltametría 
de redisolución con modificación de electrodos (Buica, Ungureanu, Birzan, Razus \& Mandoc, 2013), reportes de desarrollo y validación de un método voltamperométrico para determinar estaño total en agua (Espinoza \& Alvarado, 2008), técnicas matemáticas aplicadas a la resolución de señales electroquímicas del sistema $\mathrm{Pb}$ (ii) / TI (i) (Palacios, 2000).

El objeto del estudio fue validar y cuantificar $\mathrm{Pb}$ y $\mathrm{Cd}$ presentes en las aguas de la quebrada Las Torres (Sogamoso, Colombia) mediante la técnica de voltametría de onda cuadrada, usando electrodo carbón vítreo como electrodo de trabajo, el cual ofrece ventajas como mayor rango de potenciales positivos y negativos de trabajo, es más amigable con el entorno natural al no generar residuos, a diferencia del electrodo de gota de mercurio que se oxida a potenciales positivos y genera residuos peligrosos para el analista y el entorno natural. El trabajo permite demostrar que este método es sencillo y eficaz para la determinación de metales pesados.

\section{MATERIALES Y MÉTODOS}

\section{Materiales}

\section{Reactivos}

Todos los reactivos empleados fueron de grado analítico (RA): hidróxido de sodio ( $\mathrm{NaOH} 99 \%)$, ácido bórico $\left(\mathrm{H}_{3} \mathrm{BO}_{3} 99 \%\right)$, ácido fosfórico $\left(\mathrm{H}_{3} \mathrm{PO}_{4} 85 \%\right)$ y cloruro de sodio $(\mathrm{NaCl} 99 \%)$ de Merck, ácido acético glacial $\left(\mathrm{CH}_{3} \mathrm{COOH} 99,8 \%\right)$ y ácido nítrico $\left(\mathrm{HNO}_{3} 65 \%\right)$ de Panreac, soluciones estándar de $1000 \mathrm{mg} / \mathrm{L}$ de $\mathrm{Cd}$ y Pb marca J.T. Baker. El agua utilizada para preparación de reactivos y purgas de materiales fue desionizada con una conductividad menor de 0,3 $\mu \mathrm{S}$ (Sistema Millipore).

\section{Equipos}

Se verificaron las condiciones óptimas de funcionamiento de los equipos necesarios para la validación del método, dentro de los que se encuentran: polarógrafo BAS CV $50 \mathrm{~W}$ equipado con un analizador voltamperométrico y un electrodo de carbono vítreo BASI MF-2070 como electrodo de trabajo, electrodo de referencia Ag/AgCl BASI MF2052 y un electrodo auxiliar de platino BASI MW-1032, balanza analítica Aventure Ohaus, micropipeta Boeco de 10-100 uL y pH-metro Sartorius Scohott CG 842.

\section{Preparación de soluciones}

Se empleó una solución Buffer Britton-Robinson a pH 4,8. Se prepararon soluciones stock en agua desionizada de $\mathrm{Pb}$ y $\mathrm{Cd}$ de 100 y $30 \mu \mathrm{g} / \mathrm{L}$. La curva de calibración (0,3$1,5 \mu \mathrm{g} / \mathrm{L})$ se construyó con adiciones de 35-100 $\mu \mathrm{L}$ de las soluciones estándar a un volumen final de $7 \mathrm{ml}$.

\section{Métodos}

\section{Limpieza de sistema de electrodos}

Se realizó con ácido nítrico al 10\%, seguido de una limpieza electroquímica con cloruro de sodio saturado en modo de voltametría cíclica de 2000 a - 2000 mV durante cinco ciclos, finalmente se enjuagó con agua desionizada. 


\section{Validación de la técnica voltamétrica OSWV}

Se seleccionaron las condiciones instrumentales óptimas para el desarrollo del método como potencial inicial, potencial final, desoxigenación de la muestra, tiempo de quietud, sensibilidad, amplitud y frecuencia de onda y rango de potencial. Se determinaron los principales atributos del método de validación: límite de detección $(\mathrm{DL})$, límite de cuantificación $(\mathrm{QL})$, precisión, exactitud, rango útil, sensibilidad e incertidumbre.

\section{Comparación de resultados de voltametría de onda cuadrada frente al método espectrofotométrico de absorción atómica}

Se comparó el método voltamétrico validado con el método de referencia (espectrofotometría de absorción atómica EAA) llevando a cabo un análisis de un estándar de 2 ppm y dos muestras naturales (contramuestras) en un espectrofotómetro de llama de acetileno-aire (marca Shimadzu) con previa digestión húmeda de la muestra según método SM 3111B y SM 3030E.

\section{Cuantificación de $\mathrm{Pb}$ y $\mathrm{Cd}$ en muestras de agua natural}

Para la selección de las muestras de agua natural para el estudio se realizó un muestreo aleatorio, simple, durante los meses de agosto a noviembre de 2013 de acuerdo con un diseño experimental que cubría la totalidad del afluente quebrada Las Torres del sector Parque Industrial de Sogamoso, que recibe vertimientos de las diversas actividades empresariales. Para la medida voltamétrica se mezclaron $3 \mathrm{ml}$ de muestra previamente filtrada a través de un papel de fibra de vidrio de $47 \mathrm{~mm}$ y tamaño de poro de $1 \mu \mathrm{mm}, 0,5 \mu \mathrm{g} / \mathrm{L}$ de $\mathrm{Cd}$ y $\mathrm{Pb}$ y $4 \mathrm{ml}$ de la solución electrolítica, se ajustó a $\mathrm{pH} 4,8$. La mezcla obtenida se transfirió a la celda polarográfica, se programó el equipo según la optimización previa de los parámetros y se procedió a la medición.

\section{RESULTADOS Y DISCUSIÓN}

\section{Parámetros técnicos}

\section{Respuesta señal del equipo}

Con el objeto de conocer si el blanco seleccionado interfería con la técnica de análisis se realizó un barrido exploratorio por voltametría cíclica, seleccionando un rango de 1000 a - 200 mV (Figura 1a), no se presentó señal. La voltametría cíclica indica de forma precisa los potenciales de electroactividad de una especie química y la reversibilidad de la reacción redox que pueden presentar, es decir, si sufre un proceso de reducción y oxidación. Con el rango de potencial seleccionado se analizó un estándar de $\mathrm{Cd}$ y $\mathrm{Pb}$ para conocer su potencial de electroactividad, los metales presentaron señales a - 762 y - $542 \mathrm{mV}$, respectivamente; el voltagrama indica que los dos metales presentan reacciones reversibles (Figura 1b). Con el rango de potencial de trabajo seleccionado se evaluó la respuesta del equipo por la técnica de análisis seleccionada por su alta sensibilidad y velocidad de análisis: voltametría de onda cuadrada, se verificó que el blanco no presentara interferencia con la medida voltamétrica (Figura 1c), y se analizó un estándar de los dos metales, los cuales 
presentaron señales en potenciales de reducción en - $762 \mathrm{mV}$ para Cd y - $542 \mathrm{mV}$ para $\mathrm{Pb}$ (Figura 1d).
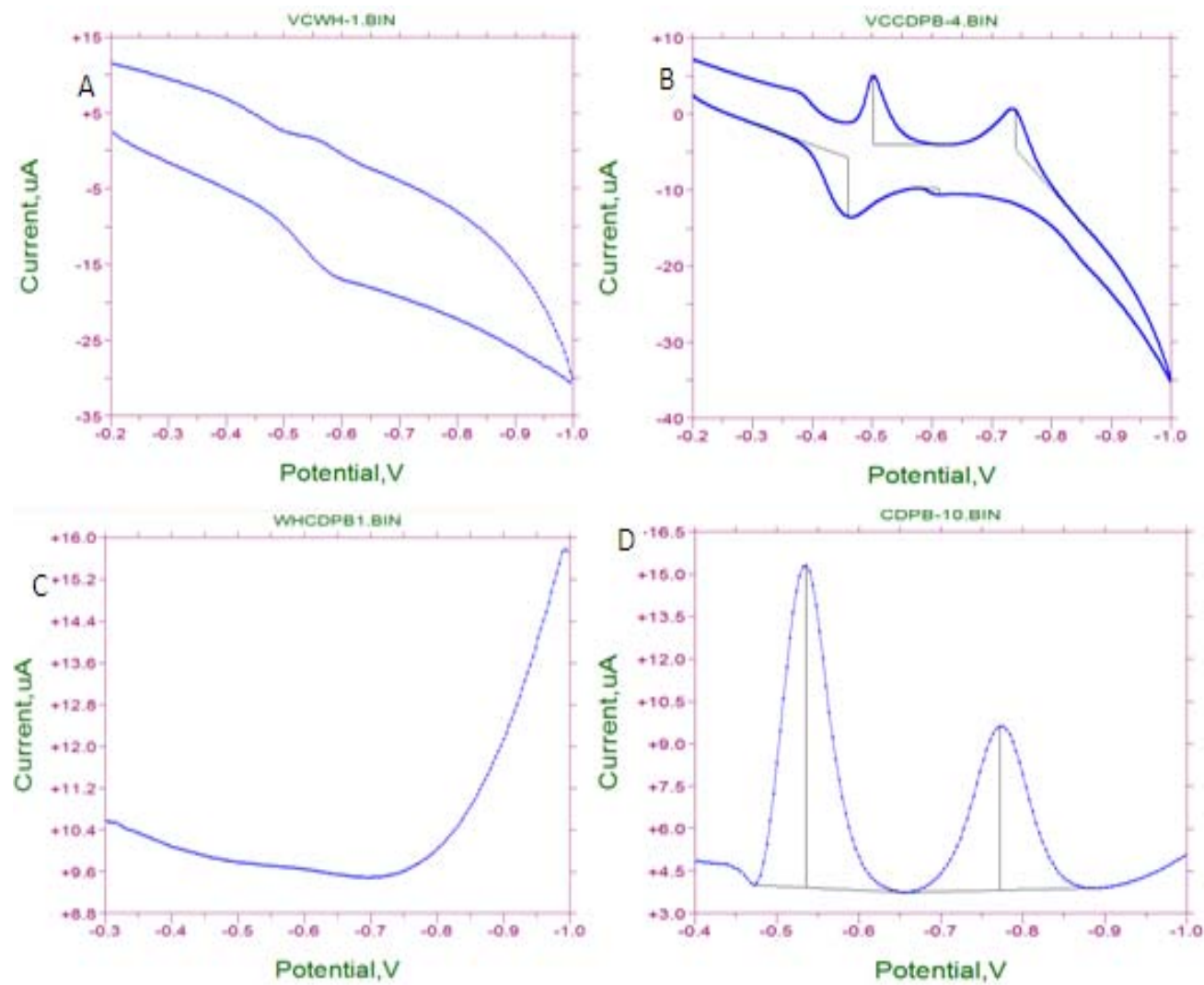

Figura 1. A: Medición del blanco por VC. B: óxido-reducción del $\mathrm{Pb}^{2+}$ y $\mathrm{Cd}^{2+}$ por VC. C: medición de blanco por OSWV. D: oxidación de $\mathrm{Pb}$ y Cd por OSWV

\section{Determinación de los parámetros para la ejecución de la medida voltamétrica}

El solvente seleccionado fue agua desionizada, se empleó como electrolito de soporte buffer Britton-Robinson (B-R) a pH 4,8. Se desarrollaron ensayos consecutivos en los cuales se modificaron y optimizaron los siguientes parámetros del equipo: desoxigenación de la muestra: 5 minutos, potencial inicial: - $1000 \mathrm{mV}$, potencial final: $200 \mathrm{mV}$, sensibilidad: $10 \mu \mathrm{A} / \mathrm{V}$, frecuencia: $15 \mathrm{~Hz}$, tiempo de quietud: 5 segundos, resistencia: $54 \mathrm{Ohm}$, amplitud de la onda cuadrada: $20 \mathrm{mV}$, muestreo: $256 \mathrm{mV}$.

\section{Selección de la curva de calibración}

Se graficó la corriente generada (amperios) en función de la concentración $(\mu \mathrm{g} / \mathrm{L})$, obteniendo la curva correspondiente de calibración (Figura 2). 

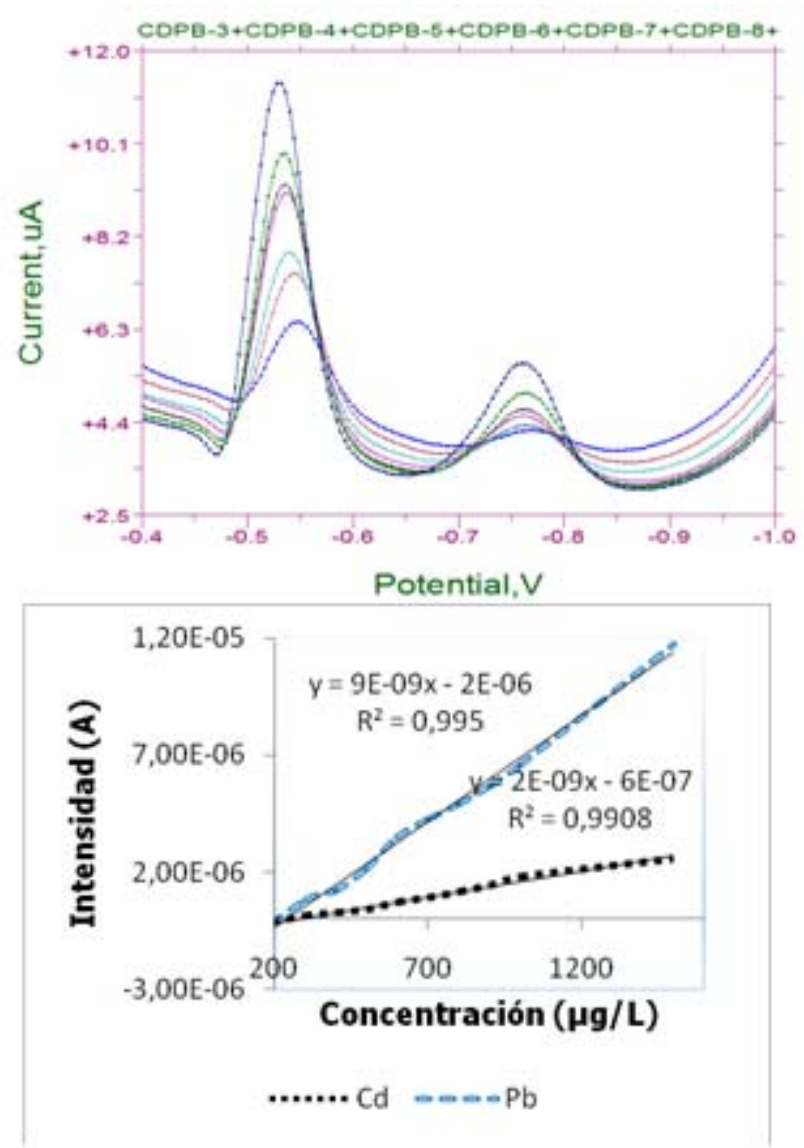

Figura 2. Curva de calibración de $\mathrm{Pb}$ y $\mathrm{Cd}$.

\section{Validación del método para cuantificación de $\mathrm{Pb}$ y $\mathrm{Cd}$}

\section{Atributos del método}

Los atributos del método de cuantificación de $\mathrm{Pb}^{2+}$ y $\mathrm{Cd}^{2+}$ por voltametría de onda cuadrada obtenidos se resumen en la Tabla 1.

Tabla 1. Atributos del método de validación para $\mathrm{Cd}$ y $\mathrm{Pb}$

\begin{tabular}{|l|c|c|}
\hline \multirow{2}{*}{ Atributo } & \multicolumn{2}{|c|}{ Valor } \\
\cline { 2 - 3 } & $\mathrm{Cd}$ & $\mathrm{Pb}$ \\
\hline Límite de detección & $268,00 \mu \mathrm{g} / \mathrm{L}$ & $211,00 \mu \mathrm{g} / \mathrm{L}$ \\
\hline Límite de cuantificación & $280,00 \mu \mathrm{g} / \mathrm{L}$ & $228,00 \mu \mathrm{g} / \mathrm{L}$ \\
\hline Sensibilidad & $2,09^{*} 10^{-9} \mathrm{~A} / \mu \mathrm{g} / \mathrm{L}$ & $8,90^{*} 10^{-9} \mathrm{~A} / \mu \mathrm{g} / \mathrm{L}$ \\
\hline Exactitud rango alto & $112,56 \%$ & $81,50 \%$ \\
\hline Exactitud rango bajo & $82,40 \%$ & $115,20 \%$ \\
\hline Precisión (reproducibilidad) & $91,60 \%$ & $89,50 \%$ \\
\hline Nivel de confianza & $94,50 \%$ & $92,00 \%$ \\
\hline Incertidumbre & $\pm 0,05 \mu \mathrm{g} / \mathrm{L}$ & $\pm 0,08 \mu \mathrm{g} / \mathrm{L}$ \\
\hline
\end{tabular}


Se determinó que las respuestas de los estándares y las muestras naturales más solución estándar en los 6 ensayos realizados por los dos analistas en el proceso de validación no presentaron variaciones significativas (Figura 3).

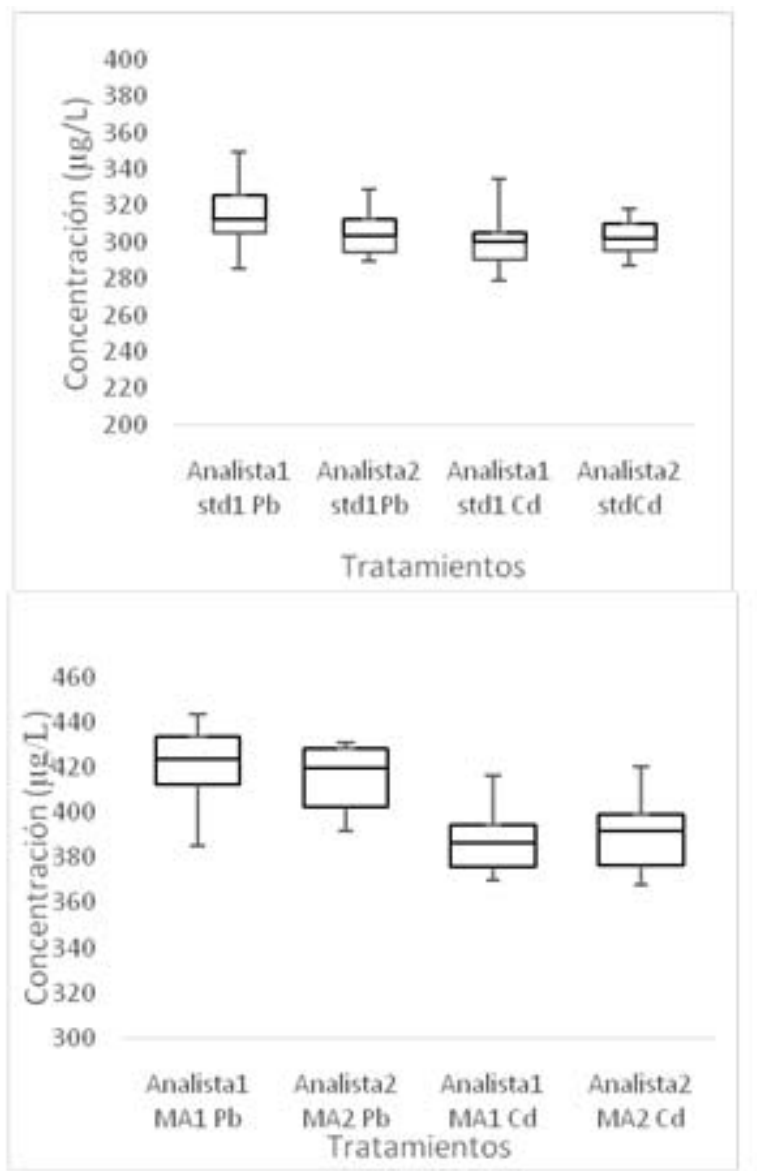

Figura 3. Análisis de varianza de dos factores con varias muestras por grupo $\mathrm{M} 1 \mathrm{~A} 1 \mathrm{Cd}-\mathrm{Pb}$.

Las medidas realizadas en las muestras naturales más adicionado (MA), presentaron mayor dispersión que los estándares de cada metal, debido posiblemente a que estas concentraciones son mayores que los estándares evaluados, sin embargo, no se presentaron diferencias significativas en los ensayos realizados por los dos analistas, datos verificados por el Análisis de Varianza, en los 6 ensayos el valor $F$ calculado fue inferior al valor $\mathrm{F}$ crítico, criterio de aceptación a un nivel de confiabilidad del 95\%.

En la Tabla 2 se presentan los resultados obtenidos por el método validado analíticamente (voltamétrico) comparado con el método de referencia (Espectrofotometría de absorción atómica). Se observa que las concentraciones de Cd y $\mathrm{Pb}$, cuantificadas en las tres muestras por voltametría de onda cuadrada, son superiores a las del método de referencia. Esta diferencia se evaluó por medio de un análisis de varianza de un factor (Tabla 3). El análisis indicó que no se presentó diferencia significativa en la concentración de los estándares de $\mathrm{Cd}$ y $\mathrm{Pb}$ determinados por las dos técnicas de análisis. El valor $\mathrm{F}$ calculado fue inferior al valor $\mathrm{F}$ crítico de aceptación. El análisis fue realizado con un nivel de confiabilidad del $95 \%$, correspondiente al método voltamétrico. 
Tabla 2. Comparación de resultados del método voltamétrico OSWV frente al método de referencia SAA

\begin{tabular}{|c|c|c|c|}
\hline \multirow{3}{*}{\multicolumn{2}{|c|}{ Muestra }} & \multicolumn{2}{|c|}{ Concentración $\mu g / L$} \\
\hline & & \multirow{2}{*}{$\begin{array}{l}\text { Voltametría de onda } \\
\text { cuadrada oswV } \\
\text { (nivel de confianza } \\
95 \% \text { ) }\end{array}$} & \multirow{2}{*}{$\begin{array}{l}\text { Espectrofotometría de } \\
\text { absorción atómica } \\
\text { SAA } \\
\text { (Nivel de confianza } \\
95 \% \text { ) }\end{array}$} \\
\hline & & & \\
\hline \multirow{2}{*}{$\begin{array}{l}\text { Muestra con estándar de } \\
\mathrm{Pb} \text { y Cd: } \mathrm{ME} 11(0,2 \mathrm{mg} / \mathrm{L})\end{array}$} & Cd & 679 & 690 \\
\hline & $\mathrm{Pb}$ & 711 & 705 \\
\hline \multirow{2}{*}{ Muestra natural: MNA-1 } & $\mathrm{Cd}$ & 364 & 359 \\
\hline & $\mathrm{Pb}$ & 347 & 339 \\
\hline \multirow{2}{*}{$\begin{array}{l}\text { Estándar de Cd y Pb: } \\
\text { SMP-2 }(0,9 \mathrm{mg} / \mathrm{L})\end{array}$} & Cd & 964 & 968 \\
\hline & $\mathrm{Pb}$ & 947 & 944 \\
\hline
\end{tabular}

Tabla 3. Análisis de varianza de un factor: estándares $\mathrm{Cd}$ y $\mathrm{Pb}$ de $0,9 \mathrm{mg} / \mathrm{L}$ determinados por voltametría de onda cuadrada y absorción atómica

\begin{tabular}{|c|l|c|c|c|c|c|c|}
\hline Técnica & $\begin{array}{c}\text { Origen de las } \\
\text { variaciones }\end{array}$ & $\begin{array}{c}\text { Suma de } \\
\text { cuadrados }\end{array}$ & $\begin{array}{c}\text { Grados } \\
\text { de } \\
\text { libertad }\end{array}$ & $\begin{array}{c}\text { Promedio } \\
\text { de los } \\
\text { cuadrados }\end{array}$ & $\begin{array}{c}\mathrm{F} \\
\text { calculado }\end{array}$ & Probabilidad & $\begin{array}{c}\text { Valor } \\
\text { crítico } \\
\text { para F }\end{array}$ \\
\hline \multirow{2}{*}{ Voltametría } & Entre grup 0s & 0,87 & 2 & 0,43 & 0,32 & 0,73 & 3,35 \\
\cline { 2 - 8 } & $\begin{array}{l}\text { Dentro de los } \\
\text { grupos }\end{array}$ & 36,60 & 27 & 1,36 & & & \\
\hline \multirow{2}{*}{$\begin{array}{c}\text { Absorción } \\
\text { atómica }\end{array}$} & \begin{tabular}{l} 
Entre grup 0s \\
\cline { 2 - 9 }
\end{tabular} & 12,87 & 2 & 6,43 & 2,31 & 0,12 & 3,35 \\
\hline
\end{tabular}

\section{Determinación cuantitativa de $\mathrm{Cd}$ y $\mathrm{Pb}$ en agua natural}

Una vez validado el método voltamétrico se procedió a su aplicación en aguas naturales. El agua analizada se tomó del afluente quebrada las Torres del sector Parque Industrial de Sogamoso que recibe vertimientos de la actividad minera de la vereda Morcá, del municipio de Sogamoso (Boyacá).

Para la medición se adicionó en la celda electroquímica $4 \mathrm{~mL}$ de la solución electrolítica Britton-Robinson y $3 \mathrm{~mL}$ de muestra natural con adición de estándar 0,5 $\mathrm{mg} / \mathrm{L}$ de $\mathrm{Cd}$ y $\mathrm{Pb}$. La concentración de cada metal fue evaluada en aguas provenientes del afluente quebrada Las Torres del sector Parque Industrial de Sogamoso, durante los meses de agosto a septiembre, con un total de 50 muestras analizadas, los datos obtenidos en promedio fueron $0,500-0,570 \mathrm{mg} / \mathrm{L}$ para $\mathrm{Cd}$ y $0,698-0,750 \mathrm{mg} / \mathrm{L}$ para $\mathrm{Pb}$, con una desviación estándar de $\pm 0,071$ y $\pm 0,067$, respectivamente. Se observó que los resultados obtenidos sobrepasan los niveles de concentración máximos permitidos en el recurso agua por las normas vigentes: Agua uso agrícola, según Decreto 1594/84 
$\left(\mathrm{Pb}^{2+}: 0,05 \mathrm{mg} / \mathrm{L}, \mathrm{Cd}^{2+}: 0,01 \mathrm{mg} / \mathrm{L}\right)\left(\right.$ MinAgricultura, 1984) y $\left(\mathrm{Pb}^{2+}: 0,015 \mathrm{mg} / \mathrm{L}\right.$ y $\mathrm{Cd}^{2+}:$ $0,005 \mathrm{mg} / \mathrm{L})$ (EPA, 2016).

Se compararon los valores del límite máximo residual MRL de los dos metales estudiados con los datos obtenidos en las muestras de agua, encontrándose que sobrepasan estos límites. Teniendo en cuenta que el agua de este afluente es empleada para uso agrícola, y que no se encuentran reportes de control de contaminantes por entes gubernamentales, los valores obtenidos permiten inferir que existe un riesgo inminente de contaminación por $\mathrm{Cd}$ y $\mathrm{Pb}$ en los productos agrícolas regados con esta agua, los cuales pueden causar problemas de salubridad al consumidor final, con mayor peligro para la población infantil en la cual el MRL en alimentos para niños es 10 veces menor que el aceptado para adultos (Li et al., 2009).

Los metales pesados son especies químicas no degradables, por tanto, se consideran contaminantes estables y persistentes al ser depositados al medio ambiente. Esto ocasiona alteraciones en los diferentes ecosistemas e incrementa su solubilidad llegando a reducir la calidad de vida de los seres vivos (Del Toro et al., 2010; Madero \& Marrugo, 2011).

La cercanía de zonas industriales con corrientes hídricas está generando residualidad peligrosa de ciertos metales entre ellos el $\mathrm{Cd}$ y el $\mathrm{Pb}$, clasificados en las categorías toxicológicas I, estos metales son acumulativos y pueden causar lesiones al sistema urinario, nervioso, reproductor e inmunológico (Soto, Lozano, Barbarín \& Alcalá, 2004; Instituto Nacional de Salud, 2014).

El monitoreo de metales pesados en alimentos es de crucial importancia para determinar el grado de exposición de una población y prevenir las posibles consecuencias toxicológicas a largo plazo, y el cambio en las prácticas culturales y la responsabilidad con el entorno natural (Yacomelo, 2014).

\section{CONCLUSIÓN}

Los atributos del método analítico voltamétrico para la cuantificación de $\mathrm{Cd}$ y $\mathrm{Pb}$ en agua natural demuestran que los resultados obtenidos son válidos y confiables. La concentración del estándar de los metales determinada por la técnica de análisis no presentó diferencia significativa. El valor $\mathrm{F}$ calculado fue inferior al valor $\mathrm{F}$ crítico de aceptación. El contenido de $\mathrm{Pb}$ y $\mathrm{Cd}$ cuantificado en agua de la quebrada las Torres del sector Parque Industrial de Sogamoso supera los niveles máximos permitidos de LMR establecidos por las normas vigentes: Decreto 1594/84 (Ministerio de Agricultura, 1984), y la tabla regulada de contaminantes en agua potable. (EPA, 2016). El análisis fue realizado con un nivel de confiabilidad del $94,5 \%$ para $\mathrm{Cd}$ y $92 \%$ para $\mathrm{Pb}$.

\section{AGRADECIMIENTOS}

Los autores agradecen el apoyo por la financiación a la Dirección de Investigaciones de la Universidad Pedagógica y Tecnológica de Colombia. 


\section{REFERENCIAS}

- Boguszewska, A., \& Pasternak, K. (2004). Cadmium-influence on biochemical processes of the human organism. Ann Univ Mariae Curie Sklodowska Med, 59(2), 519-523.

- Buica, G. O., Ungureanu, E. M., Birzan, L., Razus, A. C., \& Mandoc, L. R. (2013). Voltammetric sensing of lead and cadmium using poly (4-azulen-1-yl-2,6-bis (2thienyl)pyridine) complexing films. Journal of Electroanalytical Chemistry, 693, 6772.

- Del Toro, R., González, Y., Bravo, L. R., \& Mollineda, A. (2010). Determinación de plomo en las aguas de los ríos Tínima, Hatibonico y afluentes de la cuenca San Pedro Camagüey. Rev. Aporte Santiaguino, 3(1), 101-107.

- Environmental Protection Agency United States (EPA). (2016).Table of Regulated Drinking Water Contaminants. Recuperado de http://www.epa.gov/your-drinkingwater/table-regulated-drinking-water-contaminants\#Inorganic

- Espinoza, E., \& Alvarado, A. (2012). Desarrollo y validación de un método voltamperométrico para determinar estaño total en agua. Revista Internacional de Contaminación Ambiental, 28(1), 61-72.

- Ewing, G. W. (1997). Analytical Instrumentation Handbook. Second ed. New York: Marcel Dekker.

- Identidad Geográfica. (2015). Información General de Sogamoso. Recuperado dehttps://sites.google.com/a/sogamoso-boyaca.gov.co/biblioteca-sogamoso/sitios-deinteres/informacion-general-de-sogamoso/identidad-geografica

- Instituto Nacional de Salud. (2014). Protocolo de Vigilancia en Salud Pública. Intoxicaciones por sustancias químicas. Recuperado dehttp://www.ins.gov.co/lineas-de-accion/SubdireccionVigilancia/sivigila/Protocolos\%20SIVIGILA/PRO\%20Intoxicaciones.pdf

- Lenntech. (2015). Cadmio - Cd. Recuperado dehttp://www.lenntech.es/periodica/elementos/cd.htm\#ixzz3YjQFDImy

- Li, Y., Liu, X., Zeng, X., Liu, Y., Liu, X., Wei, W., \& Luo, S. (2009). Simultaneous determination of ultra-trace lead and cadmium at a hydroxyapatite-modified carbon 
ionic liquid electrode by square-wave stripping voltammetry. Sensor and Actuators B: Chemical, 139(2), 604-610.

- Madero, A., \& Marrugo, J. (2011). Detección de metales pesados en bovinos, en los valles de los ríos Sinú y San Jorge, departamento de Córdoba, Colombia. Revista MVZ Córdoba, 16(1), 2391-2401.

- MiNISTERIO DE AGRICULTURA. Decreto 1594 de 1984, Junio 26, Por el cual se reglamenta parcialmente el Título I de la Ley 9 de 1979, así como el Capítulo II del Título VI - Parte III - Libro I del Decreto-[Ley 2811 de 1974] en cuanto a usos del agua y residuos líquidos. Bogotá, 1984.

- Organización Mundial de la Salud (OMS). (2008). Guías para la calidad del agua potable. Tercera edición. Vol. 1: Recomendaciones. Recuperado dehttp://www.who.int/water_sanitation_health/dwq/gdwq3rev/es/

- Palacios, J. M. (2000). Técnicas matemáticas aplicadas a la resolución de señales electroquímicas del sistema Pb (II) / TI (I). (Tesis de licenciatura). Universidad de Cádiz, Cádiz, España.

- Ruiz, S. (2012). Tratamiento de muestra en la determinación de plomo en agua del río Natividad, Oxaca. (Tesis de licenciatura). Universidad de la Sierra Juárez, Ixtlán de Juárez, Oaxaca, México.

- Soto, E., Lozano, T., Barbarín, J. M., \& Alcalá, M. (2004). Remoción de metales pesados en aguas residuales mediante agentes químicos. Ingenierías, 7(23), 46-51.

- Yacomelo, M. J. (2014). Riesgo toxicológico en personas expuestas, a suelos y vegetales, con posibles concentraciones de metales pesados, en el sur del Atlántico, Colombia. (Tesis de maestría). Universidad Nacional, Medellín, Colombia.

1. Químico. Estudiante de Maestría en Química. Escuela de Posgrados. Facultad de Ciencias. Universidad Pedagógica y Tecnológica de Colombia - Grupo de Investigación en Química Ambiental. Tunja, Colombia. claudia.macias@uptc.edu.co Código Orcid: 0000-0002-3267-0768

2. Químico de Alimentos. Estudiante de Maestría en Química. Escuela de Posgrados. Facultad de Ciencias. Universidad Pedagógica y Tecnológica de Colombia - Grupo de Investigación en Química Ambiental. Tunja, Colombia.josemauricio.garcia@uptc.edu.co Código Orcid: 0000-0003-0047$281 X$. 
3. Magister en Ciencia y Tecnología de Alimentos. Docente. Escuela de Ciencias Químicas. Facultad de Ciencias. Universidad Pedagógica y Tecnológica de Colombia Grupo de Investigación en Química Ambiental. Tunja, Colombia.patricia.chaparro.uptc.edu.co Código Orcid: 0000-0002-0560-3076

Para citar este artículo: Macías Socha, C., García Colmenares, M., \& Chaparro S., P. (2016). Determinación electroquímica de plomo y cadmio en aguas superficiales. Luna Azul, 42, 27-38. DOI: 10.17151/luaz.2017.44.3

Recuperado

de http://200.21.104.25/lunazul/index.php?option=com_content\&view=article\&id=218

Esta obra está bajo una Licencia de Creative Commons Reconocimiento CC BY

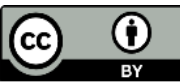

